\title{
Nanoplastics in the Environment and the Effects on the Zebrafish
}

\author{
Jimmy De León, María del C. Cotto and Francisco Márquez \\ Nanomaterials Research Group-NRG, \\ School of Natural Sciences and Technology, Universidad Ana G. Méndez-Gurabo Campus, O0778PR, USA
}

\author{
Article history \\ Received: 09-09-2019 \\ Revised: 03-10-2019 \\ Accepted: 05-10-2019 \\ Corresponding Author: \\ Jimmy De León \\ Nanomaterials Research Group- \\ NRG, School of Natural \\ Sciences and Technology, \\ Universidad Ana G. Méndez- \\ Gurabo Campus, 00778PR, \\ USA \\ Email: jde350@suagm.edu
}

\begin{abstract}
Plastic is one of the most used materials in the world, adopted in almost all activities of human life, but due to the high persistence and durability in the environment, it is causing pollution problems. Through different processes, small particles of polymers are emerging and the effects on the health are still unknown. The Danio rerio (zebrafish) is a model organism that serves as a reference for the assessment of the safety of Nanoplastics (NPs) and Microplastics (MPs). The effects on development, central nervous system, behavior and genetic regulation, are some of the evidences that are already available thanks to the studies developed in recent years. The potential exacerbation of toxicity by co-exposure of the NPs and MP with other contaminants has been demonstrated through several studies. Furthermore, the challenge that must be overcome is the lack of uniformity in the analytical methodology that helps to generate conclusive and parallel results.
\end{abstract}

Keywords: Zebrafish, Nanoplastic, Microplastic, Environmental

\section{Introduction}

One of the most used materials of our days is plastic. Plastics are compounds produced by polymerization with applications in the daily routine of ordinary people (Lenoir, 2015). At a global level, the annual production of plastics is overwhelming and the amount of these that turn into waste is certainly frightening. Environmental protectionism constantly claims the potential dangers of this waste especially for aquatic ecosystems. Geyer et al. (2017) estimate that 8300 million Metric Tons (Mt) of plastic have been produced to date and approximately for the 2015 was generated $6300 \mathrm{Mt}$ as waste of which $79 \%$ ends in the landfills. The fate of plastic can be difficult to estimate but, by simplifying, we can consider the following: (i) recycling or reuse of plastics (including applications as fuel), (ii) disposal in landfills and (iii) direct discharge into the environment. Recently a new awareness has been developed about the effects and impact on the environment and human health of small plastic particles at the micro and nanometric scale. There is no global definition of what size is considered nanometric or micrometric plastic, although the smaller the particle, the greater the potential danger. In the absence of a global, definition the United States and the European Union consider that plastic wastes with diameters of less than 5 $\mathrm{mm}$ are defined as microplastics (Alimba and Faggio, 2019). According to Rios-Mendoza et al. (2018) it is considered that there are three sources responsible for the presence of Microplastics (MP) or Nanoplastic (NP) in the environment, that can be resumed as the intentionally production of the polymers, the products of degradation of plastics in the environment and the wastewater treatment plant discharges. Besides when referring to the aquatic environment MPs can be classified by their sources as primary or secondary. Primary microplastic are generated from land sources and discharged into the aquatic environment while the secondary is referred to in situ breakdowns (Alimba and Faggio, 2019). It is real that NPs are polluting in the environment and it can directly impact ecosystems and humans. With the increase in the generation of plastic waste, the potential for bioaccumulation and transportation of these contaminants through the food chain increases. Commercial fish samples were analyzed in east China to determine the accumulation of plastic particles of more than $20 \mu \mathrm{m}$. Surprisingly, these microparticles were present in the gut and gills, although in general the smallest particles were found mainly in the gills (Su et al., 2018). Since the fish analyzed contains MP, plants and crustaceans can also be carriers of these contaminants for humans. As MPs are generally accumulated in fish guts and these parts are not commonly consumed by 
humans, the impact is not so critical. On the other hand, when these materials are processed by filtering organisms such as crabs, oysters and mussels, these organisms can accumulate MP and be later ingested by higher organisms in the trophic chain and finally by humans (Rainieri and Barranco, 2019). This material tends to be located in specific organs but not always. The behavior of small particles depends on the physicochemical properties, the environmental matrix, the size and the organism itself. The effects of MPs and NPs are not fully understood why the research aims to determine their toxicity and hazard to specific species. The research is using different model organisms to evaluate the toxic impact of MPs in the environment and results are revealing the potential hazard to the environmental health. In Artemia parthenogenetica the MPs can have effects on the intestinal epithelial cells (Wang et al., 2019). Similarly, in the Carassius auratus (goldfish) has been demonstrated sublethal effects specifically in the liver and intestines (Jabeen et al., 2018). The fish Sebastes schlegelii were exposed to MPs and some behavior characteristics were affected (Yin et al., 2018). The changes found by Yin et al. (2018) were reductions in feeding, swimming speed and in the range of movement. On the other hand, in Caenorhabditis elegans the MPs are significantly hazardous, causing lethality, reducing the level of $\mathrm{Ca}^{2+}$ ions in the intestine and increasing the expression of glutathione S-transferase 4 (Lei et al., 2018). It has been shown that Hydra attenuata can ingest microplastics that lead to some changes in morphology, reducing feeding rates (Murphy and Quinn, 2018). MPs can also cause effects on growth in Eriocheir sinensis, decreasing the activity of acetylcholinesterase, catalase and alanine aminotransferase; increasing the activity in glutathione peroxidase, superoxide dismutase and aspartate transaminase ( $\mathrm{Yu}$ et al., 2018). Daphnia magna, Daphnia pulex and Ceriodaphnia dubia were exposed to MPs and all species proved dose dependent effects on the reproductive process (Jaikumar et al., 2019). In the rat MPs can generate damage to the intestinal barrier function, causing dysbiosis of gut microbiota (Jin et al., 2019).

The Danio rerio is an appropriate model organism to study the possible effects of small plastic particles. The Danio rerio, known as zebrafish, has been widely studied in recent decades, being a basis for research that contributes significantly to the advancement of environmental toxicology. This fish is a small size vertebrate with clear embryos, external fertilization, fast reproductions, easy care and genetically broadly known. The abundant scientific resources available of zebrafish place it without doubt as one of the best models of research today. Research about NPs is proliferating and the zebrafish is leading the new studies. This model organism is in the forefront of toxicological research of engineered nanomaterials as: Silver nanoparticles, titanium oxide nanoparticles, zinc oxide nanoparticles, carbon nanotubes, copper nanoparticles, gold nanoparticles, cadmium nanoparticles and as remarked in the present review NPs (De León et al., 2019). As there is no consensus on how NPs should be analyzed, it is almost impossible to make a conclusive determination about the dangerousness of the material. The inconsistency of research results is due to the lack of standardization of quantification, characterization and sampling methods (Rios-Mendoza et al., 2018). The studies with zebrafish are starting to tie the procedures used for the analysis.

\section{NPs-MPs Effects in Zebrafish}

Zebrafish adults and embryos are been exposed to NPs and MPs to determinate the effects on the living organism and the development. The main intake of polystyrene particles was found to be through the oral consumption and not significantly by the epidermis, according Van Pomeren et al. (2017). With these findings is important that researchers consider the use of a new methodology for the exposure of adults and young fish through specific doses in food. NPs and MPs can accumulate in the fish tissues, as proved by Catarino et al. (2019) that exposed embryos to commercial fluorescent-labelled polystyrene NPs and generate the accumulation of the fluorophore in the internal tissues. Particularly the accumulation of MPs was located in the gastrointestinal tract dependently of concentration (Lemoine et al., 2018). Zebrafish also presented cracking of villi and splitting of enterocytes by MPs of $70 \mu \mathrm{m}$ size (Lei et al., 2018). To the best of our knowledge there is no prove of bio-magnification of NPs and MP, although Pitt et al. (2018b) proved that the nanopolystyrene can be transferred to the first generation of unexposed zebrafish and generate some effects on the glutathione reductase activity and thiol levels. On the other hand, the early stages of the zebrafish exposed to NP and MP can generate some serious effects on the larvae by reducing the length of the body, inhibiting the activity of acetylcholinesterase and unregulated gene expression (Chen et al., 2017a). Consequently, zebrafish larvae exposed through seven days to $100-1000 \mu \mathrm{L}$ of MPs $(5-50 \mu \mathrm{m})$ presented mayor effects on the microbiome generating energy metabolism disorder, oxidative stress, neurotoxicity and decreased activities of catalase and glutathione (Wan et al., 2019). Qiang and Cheng (2019), also reported that MPs induced upregulated expression of inflammation and oxidative stress related genes along with reductions in the swimming speed and distance of zebrafish larvae 
exposed at early stages. The presence of fluorescent polystyrene NPs during development decreased the heart rate and changed the behavior of the zebrafish larvae exposed at early stages (Pitt et al., 2018a), but, on the other hand Lemoine et al. (2018) did not find effects in terms of growth, development or metabolism despite the changes induced in gene expression.

So far, the studies reported seem to indicate that the presence of NP and PM do not represent impacts greater than those described above, although mixtures of other substances with plastics could lead to other problems. One possibility is that toxic contaminants adsorbed on the polymers are transported to the body and aggravate their exposures. Contrary to expectations, absorbed phenanthrene and $17 \alpha$-ethinylestradiol in NPs are no longer bioavailable to fish (Sleight et al., 2017). However, there is more evidence that mixtures generate more damage than simple exposure to NPs. The presence of organic matter can generate increases in the copper adsorption in small micro plastics leading to its accumulation in zebrafish liver and guts (Qiao et al., 2019). In the same research, the main toxicological effects were defined, such as increased levels of metallothionein, malonaldehyde, decreased levels of superoxide dismutase, inhibition of copper ions and enhanced oxidative stress (Qiao et al., 2019). The zebrafish exposed through food shows adverse effects only by the treatment with NPs with polychlorinated biphenyl, brominated flame retardants, per fluorinated compounds and methylmercury adsorbed on the material (Rainieri et al., 2018). Likewise, embryos exposed to polystyrene NPs induce minor effects on survival and development, but it is aggravated by the co-exposure with gold ions (Lee et al., 2019). Biphenyl A uptake into head and viscera is increased when exposed with NPs and can affect the central nervous system and dopaminergic system (Chen et al., 2017b). It seems that co-exposure effects are dependents on the adsorbed substance but the lacks of homology in the research methodology restricts conclusive statements.

\section{Conclusion}

The trend in recent years on the generation of plastic does not foresee reductions and the awareness of this dramatic problem is taking too long to inhibit the environmental impact of the byproducts. The NPs and MPs are colliding with biota and with commercial fishes. The toxic effects and mechanisms are unclear but studies with zebrafish are showing that these compounds are dangerous especially when co-contaminants are present. Research with zebrafish is beginning to align and similar protocols are apparently emerging. However, do not exist uniformity. To improve research and solve the uncertainty of NPs safety we must standardize quantification, characterization and sampling methods (Rios-Mendoza et al., 2018).

\section{Acknowledgement}

Jimmy de León thanks the US Department of Energy and Consortium for Integrating Energy Systems in Engineering and Science Education (CIESESE) for a postgraduate scholarship.

\section{Funding Information}

Financial funding from the US Department of Energy and the Consortium for Integrating Energy System in Engineering and Science Education, CIESESE (DENA0003330), is gratefully acknowledged.

\section{Author's Contributions}

All authors contributed equally to this work.

\section{Ethics}

This article is original and contains unpublished material. The corresponding author confirms that all of the other authors have read and approved the manuscript and no ethical issues involved

\section{References}

Alimba, C.G. and F. Caterina, 2019. Microplastics in the marine environment: Current trends in environmental pollution and mechanisms of toxicological profile. Environ. Toxicol. Pharmacol., 68: 61-74. DOI: 10.1016/j.etap.2019.03.001.

Catarino, A.I., A. Frutos and T.B. Henry, 2019. Use of fluorescent-labelled Nanoplastics (NPs) to demonstrate NP absorption is inconclusive without adequate controls. Sci. Total Environ., 670: 915-920.

DOI: 10.1016/j.scitotenv.2019.03.194

Chen, Q., M. Gundlach, S. Yang, J. Jiang and M. Velki et al., 2017a. Quantitative investigation of the mechanisms of microplastics and nanoplastics toward zebrafish larvae locomotor activity. Sci. Total Environ., 585: 1022-1031.

DOI: 10.1016/j.scitotenv.2017.01.156

Chen, Q., D. Yin, Y. Jia, S. Schiwy and J. Legradi et al., 2017b. Enhanced uptake of BPA in the presence of nanoplastics can lead to neurotoxic effects in adult zebrafish. Sci. Total Environ., 609: 1312-1321. DOI: $10.1016 /$ j.scitotenv.2017.07.144

De León, J., M. Cotto and F. Marquez, 2019. Toxicology of nanomaterials on zebrafish. Am. J. Eng. Applied Sci., 12: 193-203. DOI: 10.3844/ajeassp.2019.193.203

Geyer, R., J. Jambeck and K. Law, 2017. Production, use and fate of all plastics ever made. Sci. Adv., 3: e1700782-e1700782. DOI: 10.1126/sciadv.1700782 
Jabeen, K., B. Li, Q. Chen, L. Su and C. Wu et al., 2018. Effects of virgin microplastics on goldfish (Carassius auratus). Chemosphere, 213: 323-332. DOI: 10.1016/j.chemosphere.2018.09.031

Jaikumar, G., N.R. Brun, M.G. Vijver and T. Bosker, 2019. Reproductive toxicity of primary and secondary microplastics to three cladocerans during chronic exposure. Environ. Poll., 249: 638-646. DOI: 10.1016/j.envpol.2019.03.085

Jin, Y., L. Lu, W. Tu, T. Luo and Z. Fu, 2019. Impacts of polystyrene microplastic on the gut barrier, microbiota and metabolism of mice. Sci. Total Environ., 649: 308-317.

DOI: $10.1016 /$ j.scitotenv.2018.08.353

Lee, W.S., H.J. Cho, E. Kim, Y.H. Huh and H.J. Kim et al., 2019. Bioaccumulation of polystyrene nanoplastics and their effect on the toxicity of $\mathrm{Au}$ ions in zebrafish embryos. Nanoscale, 11: 3173-3185.

DOI: 10.1039/C8NR09321K

Lei, L., S. Wu, S. Lu, M. Liu and Y. Song et al., 2018. Microplastic particles cause intestinal damage and other adverse effects in zebrafish Danio rerio and nematode Caenorhabditis elegans. Sci. Total Environ., 619: 1-8. DOI: 10.1016/j.scitotenv.2017.11.103

Lemoine, C.M.R., B.M. Kelleher, R. Lagarde, C. Northam and O.O. Elebute et al., 2018. Transcriptional effects of polyethylene microplastics ingestion in developing zebrafish (Danio rerio). Environ. Poll., 243: 591-600. DOI: $10.1016 /$ j.envpol.2018.08.084

Lenoir, R.T., 2015. Global Legislation for Plastic Materials in Contact with Food. In: Global Legislation for Food Contact Materials, Baughan, J.S. (Ed.), Woodhead Publishing Series in Food Science, Technology and Nutrition, Sawston, Cambs, ISBN-10: 9781782420231, pp: 77-108.

Murphy, F. and B. Quinn, 2018. The effects of microplastic on freshwater Hydra attenuata feeding, morphology and reproduction. Environ. Poll., 234: 487-494. DOI: 10.1016/j.envpol.2017.11.029

Pitt, J.A., J.S. Kozal, N. Jayasundara, A. Massarsky and R.O. Trevisan et al., 2018a. Uptake, tissue distribution and toxicity of polystyrene nanoparticles in developing zebrafish (Danio rerio). Aquatic Toxicol., 194: 185-194.

DOI: $10.1016 /$ j.aquatox.2017.11.017

Pitt, J.A., R.O. Trevisan, A. Massarsky, J.S. Kozal and E.D. Levin et al., 2018b. Maternal transfer of nanoplastics to offspring in zebrafish (Danio rerio): A case study with nanopolystyrene. Sci. Total Environ., 643: 324-334. DOI: $10.1016 /$ j.scitotenv.2018.06.186

Qiang, L. and J. Cheng, 2019. Exposure to microplastics decreases swimming competence in larval zebrafish (Danio rerio). Ecotoxicol. Environ. Safety, 176: 226-233. DOI: 10.1016/j.ecoenv.2019.03.088
Qiao, R., K. Lu, Y. Deng, H. Ren and Y. Zhang, 2019. Combined effects of polystyrenemicroplastics and natural organic matter on the accumulation and toxicity of copper in zebrafish. Sci. Total Environ., 682: 128-137. DOI: 10.1016/j.scitotenv.2019.05.163

Rainieri, S. and A. Barranco, 2019. Microplastics, a food safety issue. Trends Food Sci. Technol., 84: 55-57. DOI: $10.1016 /$ j.tifs.2018.12.009

Rainieri, S., N. Conlledo, B.K. Larsen, K. Granby and A. Barranco, 2018. Combined effects of microplastics and chemical contaminants on the organ toxicity of zebrafish (Danio rerio). Environ. Res., 162: 135-143. DOI: 10.1016/j.envres.2017.12.019

Rios-Mendoza, L.M., H. Karapanagioti and N. RamírezÁlvarez, 2018. Micro (nanoplastics) in the marine environment: Current knowledge and gaps. Curr. Opin. Environ. Sci. Health, 1: 47-51.

DOI: 10.1016/j.coesh.2017.11.004

Sleight, V.A., A. Bakir, R.C. Thompson and T.B. Henry, 2017. Assessment of microplastic-sorbed contaminant bioavailability through analysis of biomarker gene expression in larval zebrafish. Marine Poll. Bull., 116: 291-297. DOI: 10.1016/j.marpolbul.2016.12.055

Su, L., H. Deng, B. Li, Q. Chen and V. Pettigrove et al., 2018. The occurrence of microplastic in specific organs in commercially caught fishes from coast and estuary area of east China. J. Hazardous Mater., 365: 716-724. DOI: 10.1016/j.jhazmat.2018.11.024

Van Pomeren, M., N.R. Brun, W.J.G.M. Peijnenburg and M.G. Vijver, 2017. Exploring uptake and biodistribution of polystyrene (nano) particles in zebrafish embryos at different developmental stages. Aquatic Toxicol., 190: 40-45. DOI: 10.1016/j.aquatox.2017.06.017

Wan, Z., C. Wang, J. Zhou, M. Shen and X. Wang et al., 2019. Effects of polystyrene microplastics on the composition of the microbiome and metabolism in larval zebrafish. Chemosphere, 217: 646-658. DOI: $10.1016 /$ j.chemosphere.2018.11.070

Wang, Y., D. Zhang, M. Zhang, J. Mu and G. Ding et al., 2019. Effects of ingested polystyrene microplastics on brine shrimp, Artemia parthenogenetica. Environ. Poll., 244: 715-722.

DOI: $10.1016 /$ j.envpol.2018.10.024

Yin, L., B. Chen, B. Xia, X. Shi and K. Qu, 2018. Polystyrene microplastics alter the behavior, energy reserve and nutritional composition of marine jacopever (Sebastes schlegelii). J. Hazardous Materials, 360: 97-105. DOI: 10.1016/j.jhazmat.2018.07.110

Yu, P., Z. Liu, D. Wu, M. Chen and W. Lv et al., 2018. Accumulation of polystyrene microplastics in juvenile Eriocheir sinensis and oxidative stress effects in the liver. Aquatic Toxicol., 200: 28-36. DOI: 10.1016/j.aquatox.2018.04.015 